\title{
The effectiveness of a mobile phone education- based on self-efficacy and DASH diet among patient with high blood pressure: a randomized controlled trial
}

\section{Zahra Darabi}

Ahvaz Jondishapour University of Medical Sciences

Marzieh Araban

Ahvaz Jondishapour University of Medical Sciences

Amir Abbas Azizi

Ahvaz Jondishapour University of Medical Sciences

Kambiz Ahmadi Angali

Ahvaz Jondishapour University of Medical Sciences

Fatemeh Borazjani ( $\nabla$ fa.borazjani@gmail.com )

Ahvaz Jundishapur University of Medical Sciences, Ahvaz, Iran https://orcid.org/0000-0003-2434-7757

\section{Research article}

Keywords: Hypertension, Mobile app, Trial, Self-efficacy, DASH diet.

Posted Date: September 8th, 2020

DOI: https://doi.org/10.21203/rs.3.rs-62956/v1

License: (c) (1) This work is licensed under a Creative Commons Attribution 4.0 International License.

Read Full License 


\section{Abstract}

Background: Hypertension HTN is a global public health problem with an increasing incidence worldwide. On one hand the imperative role of self-efficacy in controlling of chronic disease has been reported; on the other hand, dietary approach to stop hypertension (DASH) diet reported as one of most appropriate dietary approaches for controlling HTN. Here in present study we aimed to investigate the efficiency of mobile app for improving self-efficacy on adherence of DASH diet in HTN patients.

Methods: the present randomized controlled trial conducted on 88 patients with hypertension who referring to public health care centers between Novomber2019 to March 2020. The subjects were randomly assigned to receive mobile app for DASH-related recommendation +usual care; or control group to follow their habitual diets and given usual health care in public health care centers for twelve weeks. Self-efficacy, SBP and DBP, body mass index, physical activity and dietary intakes were assessed at the baseline and the end of trial. The ANCOVA was used to show the differences between the two groups and adjusting for baseline and covariates.

Results: Results showed that whilst there were no significant differences in DBP and SBP at the baseline, but intervention lead to significant decrease in both SBP and DBP. Results from self-efficacy showed that baseline values were not significantly different between two groups; however, all five components improved significantly at the end of trial.

Conclusion: Here we showed that using mobile apps for educating DASH diet and improving self-efficacy lead to better control of BP among patients whilst their self-efficacy improved simultaneously.

Trial registration: Iran Clinical Trials Registry: IRCT20190930044933N1.

Date of registration:31.10.2019

URL of trial registry record: https://www.irct.ir/trial/42612

\section{Background}

Hypertension (HTN), or high blood pressure (BP), is defined as when systolic and diastolic blood pressure are higher than normal range including 140 and 90 respectively. HTN is a global public health problem with an increasing incidence worldwide [1]. It is part of a clinical disease that drawn from complicated different etiologies; HTN could leads to development of complex cardiovascular disease (CVD) includes coronary artery diseases, angina and myocardial infarction [1, 2]. It has also been known to be a strong risk factor for renal failure, stroke, heart disease, and all-cause mortality and morbidity [3]. Even small decrease in BP levels, would have a remarkable effects on reducing the burden of CVD [4]. Therefore, improvement of hypertension is an imperative matter of clinical interest which may lead to significant public health benefits $[5,6]$. 
Diet and several nutrients reported to play a fundamental role in the development of hypertension [7, 8]. These factors are important, not only because they have been contributed to the etiology of HTN and CVD events, but also because they can be modulated [9]. Therefore, this makes them one of the most important goals for interventions aimed at the prevention/improvement of HTN [10-12]. Assessment of dietary patterns instead of single foods or dietary components could provide a more efficient thoughtful of how these dietary components could equally impact the risk of CVD mortality [13]. According to guidelines of the American Heart Association patients with HTN should follow certain dietary modifications $[14,15]$. However different guidelines recommended for HTN which are not comprehensive and aligned $[14,15]$. Long-standing evidence shows that consumption of specific food groups including whole grains, fruit, nuts, legumes and dairy products is associated with significant decrease in hypertension risk [16].

Dietary Approaches to Stop Hypertension (DASH) is an eating pattern that emphasize on consumption of fruits, vegetables, whole grains and also low-fat dairy products; It also contain small amounts of dietary sodium, saturated fat, meat and sweetened beverages. DASH is one of the most generally recommended dietary modifications for reducing BP and CVD risk $[17,18]$.

Self-efficacy defined as individual's sureness in their ability and capability to successfully plan and participate through with a series of actions that will result in anticipated outcomes [19]. Previous studies showed the fundamental role of self-efficacy with better self-caring process of chronic disease [20-23]. In fact, people with higher self-efficacy tend to set higher goals and anticipate greater outcomes; they will preserve in the challenge without leaving the situation. In the context of chronic diseases, patients will be more able to communicate with their physicians; they are more capable for dealing with depression and also taking their medication [24].

Different mobile health apps have gained more interest for delivering health programs to patients. Nowadays more than 100,000 of these health-related apps used by different patients with different situation [25]. Many of these health-related behavior apps also has been introduced for people suffering from hypertension; in fact, the apps recommend different actions for self-management of their disease through several activities like reminders, evidence-based information and feedbacks $[26,27]$. Here in present study we aimed to investigate the efficiency of mobile app for improving self-efficacy on adherence of DASH diet in HTN patients. We hoped that findings of present study could be useful to inform HTN patients regarding the DASH diet.

\section{Method}

\subsection{Participants}

All participants aged between 30-69 years with established high blood pressure according to available guidelines[28]; All subjects were recruited to present study between Novomber2019 to March 2020, from Ahvaz Jundishapour University of Medical Sciences (AJUMS)-affiliated public health care centers, Ahvaz, Iran (Fig. 1). This study is reported in line with CONSORT guideline. Inclusion criteria were as follows: 
patient have desire to participate; aged more than 25 years old; Patients with disease history of at least 12 months before the day of inclusion; BMI > 25 in fact overweight or obese subjects; taking the antihypertensive drug(s) dose at least for 6 months; having smart phone, having phone literacy; residence of Ahvaz city. Subjects were not included in present study if they had history of renal, arrhythmia, gastrointestinal, hepatic, endocrinological or hematological disease; In addition following patients were also excluded with participate in another study simultaneously; follow an specific diet regime; without intention for continuing study; change in the doses of anti-hypertensive drugs and treatment status. The compliance of patients were checked by phone call and text massage weekly.

All procedures were in keeping with Declaration of Helsinki. All the subjects filled up written informed consent. Study protocol has been approved by the Ahvaz Jundishapur University of Medical Sciences ethical committee (IR.AJUMS.REC.1398.419). The present study was registered in the Iranian Registry of Clinical Trials IRCT20190930044933N1.

\subsection{Study design:}

Present study was randomized controlled clinical trial. All subjects from urban public health care center randomly allocated in two different groups by 8 strata for age $(30-39 ; 40-49 ; 50-59 ; 60-69)$ and gender (male and female). Randomization was obtained using computer generated random number by computer assistant. Intervention group who receive mobile app for DASH-related recommendation; this group also receive usual health-related recommendation texts. The participants were strictly advised follow all recommendations and adjust their nutritional habits, Compliance to the intervention was controlled through phone interviews, weekly and short text massage. The control group received usual health-related recommendation in public health care centers.

\subsection{Sample size calculation}

Sample size calculated according to type one (a) and type two errors (b) as 0.05 and 0.20 (power $=80 \%$ ), respectively. Based on previous published study standard deviation (SD) and mean difference of systolic blood pressure $82.52 \pm 3.28$ and $84.84 \pm 3.69$ for DASH diet and control group respectively [29]. The sample size determined based on comparing mean of two group of treatment. Because of possible $20 \%$ reduction, the total of 44 participants were anticipated for each arm of study.

\subsection{Anthropometry and physical activity assessment:}

Body weight was measured in negligible clothes without shoes by the use of a digital scale (Seca, Hamburg, Germany) to the nearest $0.1 \mathrm{~kg}$. Height was calculated to the nearest $0.1 \mathrm{~cm}$ by using an inelastic tape measure (Seca, Hamburg, Germany). BMI also was calculated according to established formula [30].

Physical activity level has been evaluated at the beginning and at the end of intervention through Iranian international physical activity questionnaire (IPAQ). Therefore, physical activity level of all participants were reported in metabolic equivalent of task (MET) minutes/week [31].।

\subsection{Nutritional, general and medical history assessment:}


All patents completed a general questionnaire comprising different variables (including age, sex) and lifestyle habits (including the history of smoking, alcohol consumption); medical and drug history (heart and family history of diseases, hypertension duration were also recorded in all patients.

Demographic background information of the participants was obtained according to age (through openended question), education level (<12grade vs. $>12$ grade), family income status (good, moderate, poor).

Dietary intake was measured using a diet recall for 3 days (including 2 working days and 1 weekend day) a week before and at the end of intervention and average of them were reported. The dietary record were analyzed using Nutritionist IV software (First Databank, San Bruno, CA, USA) adjusted for Iranian foods[32, 33]. The score for DASH diet adherence was computed according to nine target nutrients, specifically total fat,saturated fat, protein (indexed to total energy intake),fiber,cholesterol, calcium,magnasoum,sodium and potassium. Then, micronutrients were expressed per $1000 \mathrm{kcal}$ and DASH score was made by the sum of all nutrient target value (maximum 9): a value 1 was considered for participant who met the DASH target for a nutrient, a value of 0.5 was given if met the intermediated target and the value of zero was assigned if neither target was met. DASH adherence was considered by a total score of $\geq 4.5$ out of 9 [34].

Hypertension was defined as blood pressure $\geq 130 / 85 \mathrm{mmHg}$ based on reliable guidelines[28];. SBP and DBP were measured twice after a 10-min rest using Citizen digital blood pressure monitor. The average of the two measurements was used for analysis[35].

\subsection{Self-efficacy questionnaire:}

Self-efficacy questionnaire in weight management firstly introduced by Clerk et al[36]. This questionnaire evaluates the different believes of participants to their life`s event. The present questionnaire contains 30 different questions in which based on Likert scoring they could gain between 0 to 4 score. The minimum and maximum of scores could be between 0_120. Higher scores showed higher self-efficacy of participants to his/her abilities. Estimated alpha Cronbach for reported to be between 0.7 to 0.9 . Selfefficacy questionnaire validated for Iranian population by Navidian et al.[37]; they reported appropriate validity and reliability for Iranian population.

\subsection{Mobile app and text messages:}

Smart phone app was Android-based offline application which contain DASH diet recommendations on the basis of self-efficacy. It also includes a two separate realistic short videos were considered into application. One from hypertensive patient who follow DASH diet and concluding remarks of nutrition expert for emphasizing the importance of nutrition in controlling HTN. In addition in other video, the importance of the Dash diet in controlling hypertension was stated from the point of view of a specialist of dietetics. The concept of the program has been designed to improve the self-efficacy of participants. All recommendations in this application were based on accepted guidelines in this context. In addition an integrated message send to all participants by phone call and text messages as reminder in specific time points. 


\subsection{Statistical analysis}

Normal distribution of all variables was tested by the Kolmogorov-Smirnov test. All measured variables expressed as mean and standard deviation (SD) for quantitative variables or number and percentage for qualitative variables. To compare continuous variables with normal and abnormal statistical distribution, paired sample t test and Wilcoxon test were used to compare the results within groups at the end of trial respectively. An independent sample t test with normal and Mann-Whitney test with abnormal statistical distribution were performed to compare the results between the two groups at the end of trial. Analysis of covariance (ANCOVA) was performed to identify any differences between the two groups at the end of the study, adjusting for baseline value (nutrients, Age, BMI, physical activity, component of self-efficacy). $\mathrm{P}<$ 0.05 was considered as statistically significant. All statistical analyses were performed by the Statistical Package for Social Science version 17(SPSS Inc., Chicago, Illinois, USA).

\section{Results}

Eventually 88 patients enrolled in present study; all participants included in last analysis. As presented in Table 1, at the beginning of intervention, the demographic characteristics, were not significantly different between two groups. Food record information also showed that in the entrance there were no significant differences between two groups in dietary intake of total energy, carbohydrates, proteins, fats and the only fibers was significant (Table 1). Table 2 represents the effect of intervention on blood pressure and self-efficacy components. Independent sample t-test showed that whilst there were no significant differences in DBP and SBP at the baseline, but intervention lead to significant decrease in both SBP and DBP. Results from self-efficacy showed that baseline values were not significantly different between two groups; however, all five components improved significantly at the end of trial as outlined in the Table 2. 
Table 1

Characteristics of the two groups at the baseline and end of study.

\begin{tabular}{|c|c|c|c|}
\hline $\begin{array}{l}\text { Patients characteristics and } \\
\text { macronutrients }\end{array}$ & $\begin{array}{l}\text { Intervention group }(n= \\
44) \\
\text { mean } \pm \text { SD }\end{array}$ & $\begin{array}{l}\text { Control group }(n= \\
44) \\
\text { mean } \pm \text { SD }\end{array}$ & $\begin{array}{l}\mathrm{P} \text { - } \\
\text { value }\end{array}$ \\
\hline No.of patients(female\%) & 48.9 & 51.1 & 0.6 \\
\hline Age(year) & $49.45 \pm 10.1$ & $49.42 \pm 9.63$ & 0.9 \\
\hline Income status (\%) & 69.2 & 30.8 & 0.9 \\
\hline Good & 50.9 & 49.1 & \\
\hline \multicolumn{4}{|l|}{ poor } \\
\hline Education status (\%) & $62.5 \%$ & $37.5 \%$ & 0.3 \\
\hline$\leq 12$ grade & $48.8 \%$ & $51.2 \%$ & \\
\hline \multicolumn{4}{|l|}{$>12$ grade } \\
\hline Physical activity(Met min/week) & $1989.96 \pm 1163.83$ & $1780.40 \pm 1036.93$ & 0.2 \\
\hline BMI $\left(\mathrm{kg} / \mathrm{m}^{2}\right)$ baseline & $29.51 \pm 2.89$ & $28.53 \pm 2.57$ & 0.1 \\
\hline \multirow[t]{2}{*}{ End of trial } & $29.40 \pm 2.91$ & $28.64 \pm 2.62$ & 0.2 \\
\hline & $P=0.002$ & $P=0.05$ & \\
\hline HTN duration ,(n) & 30 & 28 & 0.5 \\
\hline Less than 5 year & 14 & 16 & \\
\hline \multicolumn{4}{|l|}{ More than 5 year } \\
\hline Calories (kcal/d) baseline & $2628.55 \pm 437.36$ & $2806.33 \pm 874.62$ & 0.3 \\
\hline \multirow[t]{2}{*}{ End of trial } & $2387.34 \pm 409.61$ & $2618.96 \pm 362.45$ & 0.006 \\
\hline & $P=0.0001$ & $P=0.5$ & \\
\hline $\operatorname{Protein}(\mathrm{g} / \mathrm{d})$ baseline & $83.29 \pm 16.04$ & $77.80 \pm 14.64$ & 0.06 \\
\hline \multirow[t]{2}{*}{ End of trial } & $88.14 \pm 14.71$ & $79.75 \pm 15.67$ & 0.01 \\
\hline & $P=0.05$ & $P=0.0001$ & \\
\hline Fiber (g/1000 Kcal) & $12.40 \pm 4.47$ & $16.61 \pm 3.35$ & 0.0001 \\
\hline baseline & $14.93 \pm 4.97$ & $16.21 \pm 0.51$ & 0.07 \\
\hline End of trial & $P=0.001$ & $P=0.3$ & \\
\hline
\end{tabular}




\begin{tabular}{|llll|}
\hline $\begin{array}{l}\text { Patients characteristics and } \\
\text { macronutrients }\end{array}$ & $\begin{array}{l}\text { Intervention group }(\mathrm{n}= \\
\text { 44) } \\
\text { mean } \pm \text { SD }\end{array}$ & $\begin{array}{l}\text { Control group }(\mathrm{n}= \\
\mathbf{4 4}) \\
\text { mean } \pm \text { SD }\end{array}$ & $\begin{array}{l}\text { P- } \\
\text { value }\end{array}$ \\
\hline Fat(g/d) baseline & $66.46 \pm 20.40$ & $66.99 \pm 21.39$ & 0.9 \\
End of trial & $56.87 \pm 20.56$ & $61.99 \pm 17.3$ & 0.03 \\
& $\mathrm{P}=0.0001$ & $\mathrm{P}=0.0009$ & \\
\hline Carbohydrate(g/d) baseline & $215.57 \pm 36.61$ & $201.43 \pm 42.13$ & 0.09 \\
End of trial & $192.25 \pm 40.12$ & $192.51 \pm 40.30$ & 0.9 \\
\hline & $\mathrm{P}=0.0001$ & $\mathrm{P}=0.03$ & \\
\hline Data are shown as mean \pm standard deviation or number $(\%)$. & & \\
\hline
\end{tabular}


Table 2

, the average and standard deviation of self-efficacy components, blood pressure and BMI difference between intervention and control groups in crude and adjusted models.

\begin{tabular}{|c|c|c|c|}
\hline Factors components & Intervention group & Control group & $\begin{array}{l}\mathrm{Pb}_{-} \\
\text {value }\end{array}$ \\
\hline F1 baseline (mean \pm SD) & $12.05 \pm 8.33$ & $14.2 \pm 6.33$ & 0.2 \\
\hline F1 end of trial & $21.72 \pm 2.9$ & $9.26 \pm 6.65 p=0.0001$ & 0.001 \\
\hline M1 Mean(95\%Cl) & $P=0.0001$ & $9.21(7.66 ; 10.76)$ & 0.0001 \\
\hline \multirow[t]{2}{*}{ M 2} & 21.78(2.22;23.33) & \multirow[t]{2}{*}{$9.35(7.39 ; 11.31)$} & \multirow[t]{2}{*}{0.0001} \\
\hline & $21.90(19.94 ; 23.86)$ & & \\
\hline F2 baseline (mean \pm SD) & $2.38 \pm 1.68$ & $2.83 \pm 2.4$ & 0.4 \\
\hline F2 end of trial & $15.52 \pm 4.63 p^{a}=0.0001$ & $5.16 \pm 4.37 \mathrm{p}^{\mathrm{a}}=0.0001$ & 0.00001 \\
\hline M1 Mean(95\%Cl) & $8.90(7.68 ; 10.12)$ & $3.99(2.78 ; 5.21)$ & 0.0001 \\
\hline M 2 & $9.0(7.97 ; 10.02)$ & $3.89(2.86 ; 4.93$ & 0.0001 \\
\hline F3 baseline (mean \pm SD) & $5.75 \pm 3.55$ & $7.11 \pm 2.39$ & 0.0001 \\
\hline F3 end of trial & $8.26 \pm 2.72 p^{a}=0.0001$ & $3.93 \pm 3.05 p=0.004$ & 0.0001 \\
\hline M1 Mean(95\%Cl) & $11.96(10.5 ; 13.43)$ & $7.89(6.43 ; 9.36)$ & 0.001 \\
\hline M 2 & $12.64(11.32 ; 13.95)$ & $7.22(5.90 ; 8.53)$ & 0.00001 \\
\hline F4 baseline (mean \pm SD) & $1.22 \pm 1.23$ & $1.64 \pm 2.03$ & 0.0001 \\
\hline F4 end of trial & $0.9 \pm 1.45 p^{a}=0.05$ & $0.81 \pm 4.43 p=0.004$ & 0.1 \\
\hline M1 Mean $(95 \% \mathrm{Cl})$ & $5.99(5.12 ; 6.85)$ & $3.88(3.02 ; 4.75)$ & 0.001 \\
\hline M 2 & $5.79(4.76 ; 6.81)$ & $4.09(3.06 ; 5.11)$ & 0.04 \\
\hline F5 baseline $($ mean $\pm S D)$ & $0.086 \pm 3.08$ & $1.23 \pm 2.56$ & 0.1 \\
\hline F5 end of trial & $0.87 \pm 1.58 p=0.08$ & $0.41 \pm 1.98 p=0.2$ & 0.4 \\
\hline M1 Mean $(95 \% \mathrm{Cl})$ & $2.89(2.6 ; 3.16)$ & $1.26(1.0 ; 1.53)$ & 0.0001 \\
\hline M 2 & $2.86(2.55 ; 3.17)$ & $1.29(0.98 ; 1.60)$ & 0.0001 \\
\hline $\begin{array}{l}\text { BP. Systolic(mm Hg) baseline } \\
\text { (mean } \pm \text { SD) }\end{array}$ & $150.43 \pm 10.19$ & $155.88 \pm 16.81$ & 0.06 \\
\hline \multirow{2}{*}{ End of trial } & $144.65 \pm 10.36$ & $161.09 \pm 17.46$ & 0.0001 \\
\hline & $P=0.0001$ & $P=0.0001$ & 0.0001 \\
\hline M1 Mean $(95 \% \mathrm{Cl})$ & $144.76(140.51 ; 149.007)$ & $160.98(156.74 ; 165.23)$ & \multirow[t]{2}{*}{0.0001} \\
\hline & $144.28(137.29 ; 151.28)$ & $161.46(154.46 ; 168.45)$ & \\
\hline
\end{tabular}




\begin{tabular}{|c|c|c|c|}
\hline Factors components & Intervention group & Control group & $\begin{array}{l}\mathrm{Pb}_{-} \\
\text {value }\end{array}$ \\
\hline \multirow{2}{*}{$\begin{array}{l}\text { BP. Diyastolic }(\mathrm{mm} \mathrm{Hg}) \text { baseline } \\
(\text { mean } \pm \text { SD) }\end{array}$} & $94.15 \pm 7.69$ & $96.13 \pm 8.41$ & 0.7 \\
\hline & $88.59 \pm 8.34$ & $97.61 \pm 7.27$ & 0.0001 \\
\hline \multirow{3}{*}{$\begin{array}{l}\text { End of trial } \\
\text { M1 Mean }(95 \% \mathrm{Cl}) \\
\text { M } 2\end{array}$} & $P=0.0001$ & $P=0.1$ & 0.0001 \\
\hline & $88.49(86.22 ; 90.75)$ & $97.71(95.44 ; 99.97)$ & 0.0001 \\
\hline & $85.89(82.33 ; 89.45)$ & $100.31(96.75 ; 103.86)$ & \\
\hline \multirow{2}{*}{$\begin{array}{l}{ }^{\mathrm{c} B M I} \text { difference }\left(\mathrm{kg} / \mathrm{m}^{2}\right) \\
(\text { mean } \pm \mathrm{SD})\end{array}$} & $-0.10 \pm 0.20$ & $0.11 \pm 0.35$ & 0.0001 \\
\hline & $-0.11(-0.2 ;-0.022)$ & $0.12(0.03 ; 0.207)$ & 0.001 \\
\hline \multirow{2}{*}{\multicolumn{4}{|c|}{$\begin{array}{l}\text { End of trial } \\
{ }^{d} \text { M1 Mean }(95 \% C l)\end{array}$}} \\
\hline & & & \\
\hline \multicolumn{4}{|l|}{${ }^{\mathrm{e}} \mathrm{M} 2$} \\
\hline DASH score & $2.895 \pm 0.457$ & $2.931 \pm 0.534$ & ${ }^{c} 0.563$ \\
\hline Baseline (mean \pm SD) & $3.837 \pm 0.761$ & $3.875 \pm 0.699$ & 0.851 \\
\hline End of trial & ${ }^{d} P<0.0001$ & $P<0.0001$ & 0.771 \\
\hline M1 Mean $(95 \% \mathrm{Cl})$ & $3.835(3.616 ; 4.054)$ & $3.881(3.662 ; 4.100)$ & 0.787 \\
\hline M 2 & $3.837(3.626 ; 4.049)$ & $3.667(3.667 ; 4.090)$ & \\
\hline \multicolumn{4}{|c|}{$\mathrm{P}^{\mathrm{b}}$ Value = Obtained from Independent sample t-test } \\
\hline \multicolumn{4}{|c|}{$\mathrm{P}^{\mathrm{a}}=$ Obtained from paired sample $\mathrm{t}$-test. } \\
\hline \multicolumn{4}{|l|}{$\mathrm{P}^{\mathrm{c}=}$ obtained from mann-whitney } \\
\hline \multicolumn{4}{|l|}{$P^{d=}$ obtained from Wilcoxon test } \\
\hline \multicolumn{4}{|c|}{$P$ value adjusted = obtained from ANCOVA. } \\
\hline \multicolumn{4}{|c|}{$\begin{array}{l}\text { F1; negative emotions, F2; Availability and physical discomfort, F3; Availability and positive emotions } \\
\text { F4; Social pressure, F5; disease control and negative emotions. }\end{array}$} \\
\hline \multicolumn{4}{|c|}{ 'Body Mass Index difference; end of trial BMI- before trial BMI. } \\
\hline \multicolumn{4}{|c|}{$\begin{array}{l}\mathrm{d} M 1 ; \text { model } 1 \text { adjusted by Age and BMI, }{ }^{\mathrm{M}} \mathrm{M} 2 \text {; adjusted by model } 1+(\mathrm{F} 1+\mathrm{F} 2+\mathrm{F} 3)+\text { end of trial (fiber + } \\
\text { calory + sodium + fat }+ \text { activity. }\end{array}$} \\
\hline \multicolumn{4}{|c|}{ BP systolic; systolic blood pressure, BP diastolic; diastolic blood pressure. } \\
\hline
\end{tabular}




\section{Discussion}

The present study revealed that DASH diet education based on self-efficacy concept for 12 weeks with smartphone application improved the self-efficacy of subjects and reduced the blood pressure at the end intervention when compared to control group.

Improvement of self-efficacy reported to be useful tool in management of chronic diseases [38]. People with higher self-efficacy set higher goals whist people with lower self-efficacy have very low expectations for their goals when they try to make changes; they mostly give up when encounter even resolvable problems[39]. All of these drawbacks could affect plans of health staffs for improving health status of patients because it could lead to a larger likelihood of plan failure for management of chronic diseases [40].

Chronic diseases are complicated condition which need several positive health behaviors for better control. Previous studies showed that perceived self-efficacy associated with improvement in different health behaviors in both short- and long- term which lead to better control of several chronic diseases [40]. Higher self-efficacy also related with more sustainable health behaviors[41]. As the lifestyle change and maintain by self-efficacy, the possibility of management of disease may increase [42, 43].

Different methods introduced for better self-efficacy including successful performance of assigned tasks, observing other's success with common goals, verbally persuading and controlling physiological state of anxiety [40]. Different studies evaluated the effect of self-efficacy toward changing health behaviors and lifestyle to control chronic diseases. For instance, previous study in diabetes patients showed that improved self-efficacy is associated with better management of diet, exercise, SMBG, and foot care among them[44]. Others showed beneficial effects of self-efficacy in controlling wide range of diseases like cardiovascular disease[45], rheumatoid arthritis[46], chronic obstructive pulmonary disease (COPD) [47] and dialysis patients[48]. In HTN patients also improvement of self-efficacy showed better management of blood pressure in these patients[49].

DASH diet is one of most accepted dietary regimens for controlling blood pressure[17]. DASH may act through increasing plasma nitrite and also it can improve vascular endothelium's capacity to up-regulate nitric oxide (NO) [50]. In fact, due to high content of nuts, the rich source L-arginine, it can increase NO as well $[51,52]$. It can also improve vascular reactivity due to high antioxidant content. Here in present study we aimed to guide HTN patients for following DASH diet for two months. All recommendations were delivered through smart phone apps. In recent years using mobile apps for improving health-related problems has grown significantly[53-55]. In essence using these apps for HTN patients also is not an exception. Using smart phone apps showed better drug adherence in previous trial which lead to controlled blood pressure among those patients[56]. Other trials showed similar results which were improved health status in HTN patients[57]. Alessa et al. critically reviewed possible beneficial effects of using mobile apps in HTN patients. Included studies evaluated the effectiveness of the apps in lowering BP, more than 70 percent of studies reported that that using the apps led to significant decreases in SBP and DBP; authors concluded that these apps may be effective in the self-management of HTN[58]. Here 
in present study we showed that using smart phone app lead to better adherence to DASH diet; as there was a significant difference between the DASH index in each group at the end of the study. In fact, we showed that using this app improved SBP and DBP among HTN patients. In addition, self-efficacy components totally improved at the end of trial compared with control group. In fact, higher self-efficacy lead to better control of BP in these patients. In that case previous study in elderly subjects in Iran were conducted; participants were recruited in motivational classes. At the last of intervention, the mean of SBP and DBP and also the average scores of social support, self-efficacy, and quality of life improved significantly. However, were conducted in semi-experimental design and without control group [59]. Results proved in other semi-experimental study in Korean population. Results showed better self-efficacy, self-esteem along with significantly lower SBP and DBP[49]. Other cross-sectional studies also evaluated the possible association between self-efficacy and self-care management of HTN. In this regard previous study showed that better self-efficacy not only associated with increased adherence to medications, but also it leads to eating a low-salt diet and practicing weight management skills among Africa-American hypertensive patients[60]. Other study reported that better self-efficacy level was associated with lower SBP[61].

Present study has some limitations that need to be acknowledged. In this study, there are people of different ethnicities in Khuzestan province, but it was not possible to increase the sample size and make it more generalized and raise the differences between ethnicities to educate the Dash regime and evaluate self-efficacy of people. The other limitation was not able to measure the metabolic profile. However, we assigned the sample selection among the general population referring to public health care centers in Ahvaz city.

In addition, the application was designed only for device with Android operating system. However the android was affordable for the majority of people, and if someone has an iPhone, it is possible to have a device with a system of Android.

Furthermore, this is the first study to provide an offline application based on self-efficacy with a short video of the patient's satisfactory experiences following the Dash diet. Then, preparing a short video of a dietetics specialist in the form of keynote lecture on the importance of the Dash diet and healthy heart. In addition, providing information in divided section on the features of this diet in relation to weight control, blood pressure, blood lipid And sugar. Therefore, future long-term studies with large-scale design is needed before any confirm conclusion could be drawn.

\section{Conclusion}

Here in present study we showed that using mobile apps for adhering DASH diet and improving selfefficacy lead to better control of BP among patients whilst their self-efficacy improved simultaneously. However future studies are need to confirm results of present study.

\section{Abbreviations}


DASH: dietary approach to stop hypertension; HTN: hypertension; SBP: systolic blood pressure; DBP : diastolic blood pressure; App: application; CVD: cardiovascular disease; BMI: body mass index; IPAQ: international physical activity questionnaire; MET: metabolic equivalent of task; SD: standard deviation; ANCOVA: analysis of covariance; AJUMS: ahvaz jundishapur university of medical science; SMBG: selfmonitoring of blood glucose.

\section{Declarations}

Ethics approval and consent to participate: This study has been approved with ethical number (IR.AJUMS.REC.1398.419) by Research Deputy of Ahvaz Jundishapur University of Medical Sciences in accordance with the Declaration of Helsinki. Written informed consent was obtained from all participants. This study registered in Iranian clinical trial registry with code number; IRCT20190930044933N1.

Consent to publish: Not applicable

Availability of data and materials: The data that support the findings of this study are available on request from the corresponding author.

Competing interests: All authors report no competing interests .

Funding: This study was financially supported by the Research Deputy of Ahvaz Jundishapur University of Medical Sciences and to provide the funding of this research project (NRC9808).

Authors' Contributions: FB and ZD designed the study question, supervised data collection; FB,ZD and AAA cooperate in conduct mobile application ; FB,ZD and MA drafted the manuscript ;FB and KAA. Supervised all statistical modelling and interpretation of data. All authors assisted in concept and design of study, revising it critically for important intellectual content and final approval of manuscript.

Acknowledgements: This study is result of ZD's MSc dissertation and supervised by FB. We highly appreciate the Research Deputy of Ahvaz Jundishapur University of Medical Sciences and Nutrition and Metabolic Diseases Research Center to approve this research project IR.AJUMS.REC.1398.419.

\section{References}

\section{Lurbe IFE: [2016 - European Society of Hypertension Guidelines for the management of high blood} pressure in children and adolescents]. Anales de pediatria (Barcelona, Spain : 2003) 2016, 85(4):167169.

2. Motedayen M, Sarokhani D, Meysami A, Jouybari L, Sanagoo A, Hasanpour Dehkordi A: The prevalence of hypertension in diabetic patients in Iran; a systematic review and meta-analysis. Journal of nephropathology 2018, 7(3):137-144. 
3. Nasri H, Ardalan M-R, Rafieian-Kopaei R: On the occasion of world hypertension day 2014. J Parathyr Dis 2014, 2(1):5-6.

4. Entezari MH, Hadi A, Kafeshani M: Effects of dietary approaches to stop hypertension diet versus usual dietary advice on glycemic indices in women at risk for cardiovascular disease; a randomized controlled clinical trial. J Renal Inj Prev 2017, 6:205-209.

5. Bonaa KH, Thelle DS: Association between blood pressure and serum lipids in a population. The Tromso Study. Circulation 1991, 83(4):1305-1314.

6. Lee JS, Chang PY, Zhang Y, Kizer JR, Best LG, Howard BV: Triglyceride and HDL-C Dyslipidemia and Risks of Coronary Heart Disease and Ischemic Stroke by Glycemic Dysregulation Status: The Strong Heart Study. Diabetes care 2017, 40(4):529-537.

7. Appel LJ, Brands MW, Daniels SR, Karanja N, Elmer PJ, Sacks FM: Dietary approaches to prevent and treat hypertension: a scientific statement from the American Heart Association. Hypertension 2006, 47(2):296-308.

8. Pickering TG: New guidelines on diet and blood pressure. In.: Am Heart Assoc; 2006.

9. Miraghajani MS, Najafabadi MM, Surkan PJ, Esmaillzadeh A, Mirlohi M, Azadbakht L: Soy milk consumption and blood pressure among type 2 diabetic patients with nephropathy. Journal of renal nutrition : the official journal of the Council on Renal Nutrition of the National Kidney Foundation 2013, 23(4):277-282.e271.

10. Askarpour M, Ghaedi E, Roshanravan N, Hadi A, Mohammadi H, Symonds ME, Miraghajani M: Policosanol supplementation significantly improves blood pressure among adults: A systematic review and meta-analysis of randomized controlled trials. Complementary therapies in medicine 2019, 45:89-97.

11. Serban MC, Sahebkar A, Zanchetti A, Mikhailidis DP, Howard G, Antal D, Andrica F, Ahmed A, Aronow WS, Muntner P: Effects of quercetin on blood pressure: a systematic review and meta-analysis of randomized controlled trials. Journal of the American Heart Association 2016, 5(7):e002713.

12. Ursoniu S, Sahebkar A, Andrica F, Serban C, Banach M, Lipid, Collaboration BPM-a: Effects of flaxseed supplements on blood pressure: A systematic review and meta-analysis of controlled clinical trial. Clinical nutrition 2016, 35(3):615-625.

13. Ghaedi E, Mohammadi M, Mohammadi H, Ramezani-Jolfaie N, Malekzadeh J, Hosseinzadeh M, Salehi-Abargouei A: Effects of a Paleolithic Diet on Cardiovascular Disease Risk Factors: A Systematic Review and Meta-Analysis of Randomized Controlled Trials. Advances in nutrition (Bethesda, Md) 2019, 10(4):634-646.

14. Eckel RH, Jakicic JM, Ard JD, de Jesus JM, Miller NH, Hubbard VS, Lee I-M, Lichtenstein AH, Loria CM, Millen BE: 2013 AHAVACC guideline on lifestyle management to reduce cardiovascular risk: a report of the American College of Cardiology/American Heart Association Task Force on Practice Guidelines. Journal of the American College of Cardiology 2014, 63(25 Part B):2960-2984.

15. Smith SC, Benjamin EJ, Bonow RO, Braun LT, Creager MA, Franklin BA, Gibbons RJ, Grundy SM, Hiratzka LF, Jones DW: AHA/ACCF secondary prevention and risk reduction therapy for patients with 
coronary and other atherosclerotic vascular disease: 2011 update: a guideline from the American Heart Association and American College of Cardiology Foundation endorsed by the World Heart Federation and the Preventive Cardiovascular Nurses Association. Journal of the American college of cardiology 2011, 58(23):2432-2446.

16. SchwingshackI L, Schwedhelm C, Hoffmann G, Knüppel S, Iqbal K, Andriolo V, Bechthold A, Schlesinger $\mathrm{S}$, Boeing $\mathrm{H}$ : Food groups and risk of hypertension: a systematic review and doseresponse meta-analysis of prospective studies. Advances in Nutrition 2017, 8(6):793-803.

17. Sacks FM, Svetkey LP, Vollmer WM, Appel LJ, Bray GA, Harsha D, Obarzanek E, Conlin PR, Miller ER, Simons-Morton DG: Effects on blood pressure of reduced dietary sodium and the Dietary Approaches to Stop Hypertension (DASH) diet. New England journal of medicine 2001, 344(1):3-10.

18. Chiu S, Bergeron N, Williams PT, Bray GA, Sutherland B, Krauss RM: Comparison of the DASH (Dietary Approaches to Stop Hypertension) diet and a higher-fat DASH diet on blood pressure and lipids and lipoproteins: a randomized controlled trial-3. The American journal of clinical nutrition 2016, 103(2):341-347.

19. Bandura A: Health promotion from the perspective of social cognitive theory. Psychology and health 1998, 13(4):623-649.

20. Walpole B, Dettmer E, Morrongiello BA, McCrindle BW, Hamilton J: Motivational interviewing to enhance self-efficacy and promote weight loss in overweight and obese adolescents: a randomized controlled trial. Journal of pediatric psychology 2013, 38(9):944-953.

21. Richert J, Reuter T, Wiedemann AU, Lippke S, Ziegelmann J, Schwarzer R: Differential effects of planning and self-efficacy on fruit and vegetable consumption. Appetite 2010, 54(3):611-614.

22. Anderson ES, Winett RA, Wojcik JR, Williams DM: Social cognitive mediators of change in a group randomized nutrition and physical activity intervention: social support, self-efficacy, outcome expectations and self-regulation in the guide-to-health trial. Journal of health psychology 2010, 15(1):21-32.

23. King DK, Glasgow RE, Toobert DJ, Strycker LA, Estabrooks PA, Osuna D, Faber AJ: Self-efficacy, problem solving, and social-environmental support are associated with diabetes self-management behaviors. Diabetes care 2010, 33(4):751-753.

24. Lorig K, Stewart A, Ritter P, Lynch J, Gonzalez V, Laurent D: Outcome measures for health education and other health care interventions: Sage; 1996.

25. Edwards EA, Lumsden J, Rivas C, Steed L, Edwards L, Thiyagarajan A, Sohanpal R, Caton H, Griffiths C, Munafò M: Gamification for health promotion: systematic review of behaviour change techniques in smartphone apps. BMJ open 2016, 6(10):e012447.

26. Kumar N, Khunger M, Gupta A, Garg N: A content analysis of smartphone-based applications for hypertension management. Journal of the American Society of Hypertension 2015, 9(2):130-136.

27. Parati G, Torlasco C, Omboni S, Pellegrini D: Smartphone applications for hypertension management: a potential game-changer that needs more control. Current hypertension reports 2017, 19(6):48. 
28. Cardiology ACo: New ACC/AHA high blood pressure guidelines lower definition of hypertension. Retrieved March 2017, 3:2019.

29. Kucharska A, Gajewska D, Kiedrowski M, Sińska B, Juszczyk G, Czerw A, Augustynowicz A, Bobiński $\mathrm{K}$, Deptała A, Niegowska J: The impact of individualised nutritional therapy according to DASH diet on blood pressure, body mass, and selected biochemical parameters in overweight/obese patients with primary arterial hypertension: a prospective randomised study. Kardiol Po/ 2018, 76(1):158-165.

30. Cogill B: Anthropometric indicators measurement guide. 2001.

31. Moghaddam MB, Aghdam FB, Jafarabadi MA, Allahverdipour H, Nikookheslat SD, Safarpour S: The Iranian Version of International Physical Activity Questionnaire (IPAQ) in Iran: content and construct validity, factor structure, internal consistency and stability. World applied sciences journal 2012, 18(8):1073-1080.

32. Rafiei M, Boshtam M, Marandi A, Jalali A, Vakili R: The Iranian food consumption program (IFCP), a unique nutritional software in Iran. Iranian Journal of Public Health 2002:105-107.

33. Keshteli AH, Esmaillzadeh A, Rajaie S, Askari G, Feinle-Bisset C, Adibi P: A dish-based semiquantitative food frequency questionnaire for assessment of dietary intakes in epidemiologic studies in Iran: design and development. International journal of preventive medicine 2014, 5(1):29.

34. Mellen PB, Gao SK, Vitolins MZ, Goff DC, Jr.: Deteriorating dietary habits among adults with hypertension: DASH dietary accordance, NHANES 1988-1994 and 1999-2004. Archives of internal medicine 2008, 168(3):308-314.

35. Muntner P, Shimbo D, Carey RM, Charleston JB, Gaillard T, Misra S, Myers MG, Ogedegbe G, Schwartz JE, Townsend RR: Measurement of blood pressure in humans: a scientific statement from the American Heart Association. Hypertension 2019, 73(5):e35-e66.

36. Clark MM, Abrams DB, Niaura RS, Eaton CA, Rossi JS: Self-efficacy in weight management. Journal of consulting and clinical psychology 1991, 59(5):739.

37. Navidian A: Reliability and validity of the weight efficacy lifestyle questionnaire in overweight and obese individuals. International Journal of Behavioral Sciences 2009, 3(3):217-222.

38. Thombs BD, Kwakkenbos L, Riehm KE, Saadat N, Fedoruk C: Comparison of Self-Efficacy for Managing Chronic Disease between patients with systemic sclerosis and other chronic conditions: a systematic review. Rheumatology international 2017, 37(2):281-292.

39. Farley $\mathrm{H}$ : Promoting self-efficacy in patients with chronic disease beyond traditional education: A literature review. Nursing Open 2020, 7(1):30-41.

40. Mularcik KA: Self-efficacy toward health behaviors to improve blood pressure in patients who receive care in a primary care network. The Ohio State University; 2010.

41. Selzler AM, Habash R, Robson L, Lenton E, Goldstein R, Brooks D: Self-efficacy and health-related quality of life in chronic obstructive pulmonary disease: A meta-analysis. Patient education and counseling 2020, 103(4):682-692.

42. Pérez YIV, Medlow S, Ho J, Steinbeck K: Mobile and Web-Based Apps That Support Self-Management and Transition in Young People With Chronic Illness: Systematic Review. Journal of medical Internet 
research 2019, 21(11):e13579.

43. Harorani M, Zamenjani MN, Golitaleb M, Davodabady F, Zahedi S, Jadidi A, Rezaei M: Effects of relaxation on self-esteem of patients with cancer: a randomized clinical trial. Supportive Care in Cancer 2020, 28(1):405-411.

44. Sarkar U, Fisher L, Schillinger D: Is self-efficacy associated with diabetes self-management across race/ethnicity and health literacy? Diabetes care 2006, 29(4):823-829.

45. Clark NM, Dodge JA: Exploring self-efficacy as a predictor of disease management. Health Education \& Behavior 1999, 26(1):72-89.

46. Mäkeläinen P, Vehviläinen-Julkunen K, Pietilä A: A survey of rheumatoid arthritis patients selfefficacy. The Internet Journal of Advanced Nursing Practice 2007, 9(2).

47. Kara Kaşıkçı M, Alberto J: Family support, perceived self-efficacy and self-care behaviour of Turkish patients with chronic obstructive pulmonary disease. Journal of clinical nursing 2007, 16(8):14681478.

48. Zrinyi M, Juhasz M, Balla J, Katona E, Ben T, Kakuk G, Pall D: Dietary self-efficacy: determinant of compliance behaviours and biochemical outcomes in haemodialysis patients. Nephrology Dialysis Transplantation 2003, 18(9):1869-1873.

49. Kim M, Song M: Effects of self-management program applying Dongsasub training on self-efficacy, self-esteem, self-management behavior and blood pressure in older adults with hypertension. Journal of Korean Academy of Nursing 2015, 45(4):576-586.

50. Lin PH, Allen JD, Li YJ, Yu M, Lien LF, Svetkey LP: Blood Pressure-Lowering Mechanisms of the DASH Dietary Pattern. Journal of nutrition and metabolism 2012, 2012:472396.

51. Cooke JP, Tsao P, Singer A, Wang BY, Kosek J, Drexler H: Anti-atherogenic effect of nuts: is the answer NO? Archives of internal medicine 1993, 153(7):896, 899, 902.

52. Sun B, Williams JS, Svetkey LP, Kolatkar NS, Conlin PR: $\beta 2$-Adrenergic receptor genotype affects the renin-angiotensin-aldosterone system response to the Dietary Approaches to Stop Hypertension (DASH) dietary pattern. The American journal of clinical nutrition 2010, 92(2):444-449.

53. Badawy SM, Barrera L, Sinno MG, Kaviany S, O’Dwyer LC, Kuhns LM: Text messaging and mobile phone apps as interventions to improve adherence in adolescents with chronic health conditions: a systematic review. JMIR mHealth and uHealth 2017, 5(5):e66.

54. Mateo GF, Granado-Font E, Ferré-Grau C, Montaña-Carreras X: Mobile phone apps to promote weight loss and increase physical activity: a systematic review and meta-analysis. Journal of medical Internet research 2015, 17(11):e253.

55. Agarwal P, Mukerji G, Desveaux L, Ivers NM, Bhattacharyya O, Hensel JM, Shaw J, Bouck Z, Jamieson T, Onabajo N: Mobile app for improved self-management of type 2 diabetes: multicenter pragmatic randomized controlled trial. JMIR mHealth and uHealth 2019, 7(1):e10321.

56. Márquez EC, Márquez SR, Rodríguez EG, López-García-Ramos L, Pastoriza JV, Baldonedo AS, Gracia CD, Gil VG, Martell NC: Specific hypertension smartphone app to improve medication adherence in hypertension: a cluster-randomized trial. Current medical research and opinion 2018:1-15. 
57. Kang H, Park H-A: A mobile app for hypertension management based on clinical practice guidelines: development and deployment. JMIR mHealth and uHealth 2016, 4(1):e12.

58. Alessa T, Abdi S, Hawley MS, de Witte L: Mobile apps to support the self-management of hypertension: systematic review of effectiveness, usability, and user satisfaction. JMIR mHealth and uHealth 2018, 6(7):e10723.

59. Mohamadian H, LATIFI S, MORADGHOLI A: Effect of Motivational Interviewing on Hypertension, selfcare and Quality of Life of Rural Aged People: Application of Health Belief Model. 2019.

60. Warren-Findlow J, Seymour RB, Huber LRB: The association between self-efficacy and hypertension self-care activities among African American adults. Journal of community health 2012, 37(1):15-24.

61. Harmell AL, Mausbach BT, Roepke SK, Moore RC, von Känel R, Patterson TL, Dimsdale JE, Mills PJ, Ziegler MG, Allison MA: The relationship between self-efficacy and resting blood pressure in spousal Alzheimer's caregivers. British journal of health psychology 2011, 16(2):317-328.

\section{Figures}


Excluded $(n=122)$

- Not meeting inclusion criteria $(n=64)$

- Declined to participate $(n=35)$

- Other reasons $(n=23)$

Randomized $(n=88)$

Intervention $(\mathrm{n}=44)$

- Received mobile application of DASH diet+usual public health care $(n=44)$ -

(installation of application ,Self-efficacy , diet recall,physical activity, $\mathrm{BMI}$, blood pressure were assessed at baseline)

\section{Allocation}

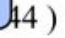

- Received usual public health care $(n=44)$

(Self-efficacy, diet recall,physical activity,BMI,blood pressure were assessed at baseline)

\section{Follow-Up 12 weeks}

(The participants remind to use the application trough sending mobile text message during week)

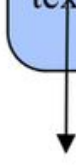

\section{Figure 1}

Flow chart

\section{Supplementary Files}

This is a list of supplementary files associated with this preprint. Click to download. 
- CONSORT2010Checklist.Aug.2020.doc 